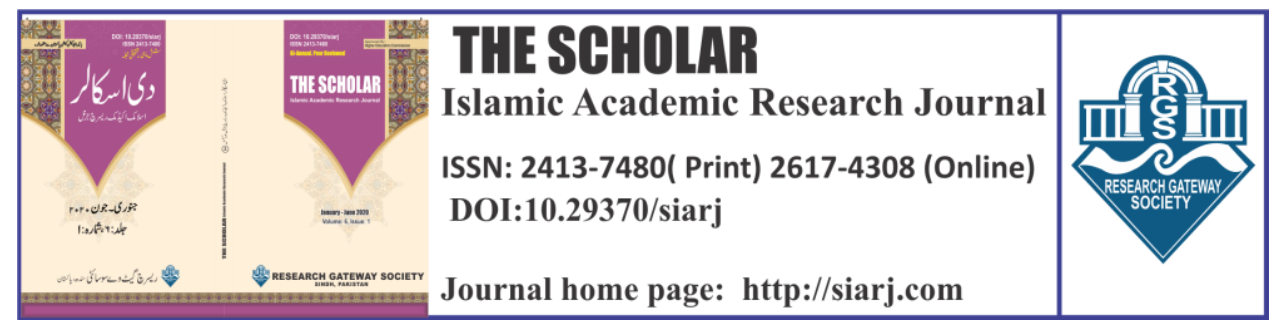

\title{
THE UPSHOTS AND SOCIO-CULTURAL CHARACTER FOR MUSLIM WOMEN IN ISLAMIC SOCIETY
}

\section{Rizwana Jabeen}

Assistant Professor, Federal Urdu

University, Karachi.

Email: rizjab2003@hotmail.com

ORCID IID:

https://orcid.org/0000-0002-9051-1714
2. Mamnoon Ahmed Khan

Assistant Professor, Federal Urdu

University, Karachi

Email: mamnoonak@gmail.com

ORCIID IID:

https://orcid.org/0000-0003-0348-3346

\section{Maryam Bibi}

Assistant Professor, Jinnah University for Women, Karachi.

Email: maryam.shah5@gmail.com

ORCIID IID: https://orcid.org/0000-0003-4409-5761

To cite this article:

Jabeen, Rizwana, Mamnoon Ahmed Khan, and Maryam Bibi. "THE UPSHOTS AND SOCIO-CULTURAL CHARACTER FOR MUSLIM WOMEN IN ISLAMIC SOCIETY." The Scholar-Islamic Academic Research Journal 6, No. 1 (May 31, 2020): 304-352.

To link to this article: https://doi.org/10.29370/siarj/issue10aren21

\begin{tabular}{|c|c|}
\hline Journal & $\begin{array}{l}\text { The Scholar Islamic Academic Research Journal } \\
\text { Vol. 6, No. } 1 \text { || January -June } 2020 \text { || P. 304-352 } \\
\text { Research Gateway Society }\end{array}$ \\
\hline Publisher & Research Gateway Society \\
\hline DOI: & 10.29370/siari/issue10aren21 \\
\hline URL: & https://doi.org/10.29370/siarj/issue10aren21 \\
\hline License: & Copyright c 2017 NC-SA 4.0 \\
\hline Journal homepage & www.siari.com \\
\hline Published online: & $2020-05-31$ \\
\hline
\end{tabular}

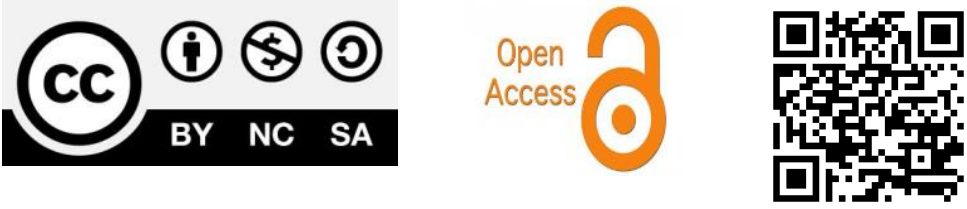


THE SCHOLAR (January- June 2020)

\title{
THE UPSHOTS AND SOCIO-CULTURAL CHARACTER FOR MUSLIM WOMEN IN ISLAMIC SOCIETY
}

Rizwana Jabeen, Mamnoon Ahmed Khan, Maryam Bibi

\begin{abstract}
:
Social advances and legal-based socio-cultural scholars have argued that "character legislative issues" weaken social advances and undermine their effectiveness in an open approach. I put forward the imaginary argument that some kind of "character assembly issues" could have the opposite impact. In particular, when composing underestimated clusters around the characteristics of a "network area", they master the local crowd, create feelings associated with the growth of strong members, and do alert work programs as well as create modules for comprehensive alliances. The U.S. In revealing, personal business material through colorful women strengthens the growth of women and does not legally enhance the reaction of experts to a shadow of a shadow against women and brutality against women. This article will be a focus on how and why the enemy usually spreads sex to seize power in the public arena, rather than acting out government issues in the cultural and religion. The article focuses mainly on the penances of women and their area as different personalities around in the Islamic Society.
\end{abstract}

KEYWORDS: Cultural identity, socio-cultural ethics, women's competition, Westernization, Islamic society.

\section{INTRODUCTION:}

Enthusiasm for the concept of identity has grown exponentially during the most recent decade within humanity and personality. Recent human philosophers have tested the origins of culture by arguing that the 
entrenched theme of free public consultation is the erroneous date to be inserted by the adaptable person with his or her fluid, unpredictable and developed social personality (Butler, 1990; Novotny, 1998; Vallencourt Rosenau, 1992; Jr., 1997). Social researchers have also increased their motivation to stay longer with the character's view more recently (Jenkins, 1996). Social scientists have analyzed and investigated the pressure between a single character and the needs of a social structure (Giddens, 1991; Jenkins, 1996; Stryker, 1980). Anthropologists have studied the character's social manifestations, their effects, and how they are kept within group boundaries (Barth, 1969; Cohen, 1986). Social therapists have entered a state of multifaceted and unpredictable personalities (Gergen, 1971; Hogg, Terry, and White, 1995; Markus, 1977). They have also seen the social way of life as an astonishing adjustment to the continuation of group conflict and factional conflict (Tajfel, 1981; Turner, Hogg, Oakes, Reicher, and Wetherell, 1987). Human dialogue has had a smaller impact than usual, it would have been, in the investigation of the plurality of socio-cultural ethics as a rule and in the exploration of sociocultural explicit politics. Despite the ongoing development of government affairs around Islamic society, socio-cultural ethics experts have been slow to join the character's view in their experimental investigations. This view is bizarre, considering that applications for mass recognition and acceptance are at the heart of a new social movement fighting for women's rights, the brave minority, discriminated racial groups, and homosexuals (Taylor, 1994). ${ }^{1}$

\footnotetext{
${ }^{1}$ Leonie Huddy; (March 2001); From Social to Socio-cultural Identity: A Critical Examination of Social Identity Theory
} 
The social character hypothesis is important for a number of reasons. It has produced a plethora of lessons at a separate international conference (see Brewer and Brown, 1998). Its key findings, perhaps the most popular of the group's rise in non-essential conditions, have been extensively documented (Brewer, 1979; Brown, 1995). It has also created experimental ideas that can be used in many forum structures, including those connected to legal issues. Ultimately, it tends to have certain types that are important to socio-cultural analysts - combining conflicts, level adjustments, the effects of low-level interactions and situations in which it produces collective work, and factors that improve your order as other people in circles. ${ }^{2}$

Although Islamic society is known as a global city in the present era, the identity-based socio-cultural structure is still diligent in specific structures. From earlier days, people have acquired character or will undoubtedly get one. Issues of linguistic and religious ethnic roles in a collection of experiences and developments in the multi-ethnic countries of the former Soviet Union, Eastern Europe, Africa and South Asia. This article argues that while the way of life of a group living within a particular region is safe in the neighbourhood, the issue in question is not really the tolerance of a particular culture, but the socio-cultural, monetary and social needs of specific individuals. An essential concern in the socio-cultural structure of multinational countries is the fear of mastery or abuse in certain ethnic

file:///C:/Users/admin/Downloads/From_Social_to_Sociocultural_Identity_A_Critical_Exami.pdf

2 Alita NandiORCID \&Lucinda PlattORCID; (Nov 16, 2018); "The relationship between socio-cultural and ethnic identity among UK ethnic minority and majority populations" https://www.tandfonline.com/doi/full/10.1080/1369183X.2018.1539286 
groups and being absorbed by other ethnic groups. As this issue is real and manifests with the development of an advanced commonwealth, moral thinking has been taken out of the general strategic preparation by these states. Such countries include Pakistan, which has different ethnic identities and testify to some of the socio-cultural affiliations of the general nature of the conspiracy these days ${ }^{3}$

Apart of mentioning the consolidates of Pakistan let's turn to the truth eye sighting concept of socio-cultural identities and how gender insurgences exist when it comes to women's role in politics, education, career and social compatibility of democratic policies and negotiation in countries in west and European hemisphere. Before resiliently describing the impact over women through identity politics, initiatively we have to analysis what is socio-cultural identity from the very beginning and what Islamic teaching aspires socio-cultural identity has a future reference to humanity in modern nation-state paradigm?

The reason for personality, religion, and identity has distinction and join. It is relentless to use that characters make concerning nation, religion, sex, language, budgetary work and lifestyle. While characters are not, now consistent or unidimensional, they can similarly moreover be implicit a way which is awe-inspiring of some specific component of character plan. For example, it is battled through whatever as regular French Republicans - that a standard we of expansive distinctive evidence can't be obliged with a non-normal public character. As shown by this view, the public house can't oblige nonstandard pictures, for instance, the hijab (headscarf).

3 Muhammad Shahada; (January 2009);" The Politics of Identity" https://www.researchgate.net/publication/260286911_The_Politics_of_Identity 
The Upshots and Socio-Cultural Character for Muslim Women in Islamic Society

The issue genuine here is that the hijab may likewise be a presentation of conspicuous verification authoritative issues, used to pass on a message in the open field: a message that isn't about certainty basically, at any rate about differentiation and an ideal for public affirmation. Character administrative issues, in such manner, asserts separation to the extended capabilities in tastes, lifestyles and strategies for portrayal in the open field. ${ }^{4}$

\section{WOMEN IN THE HOLY QURAN \& HADITH}

The Qur'an declares that men and women are equal in terms of reward and punishment; it states,

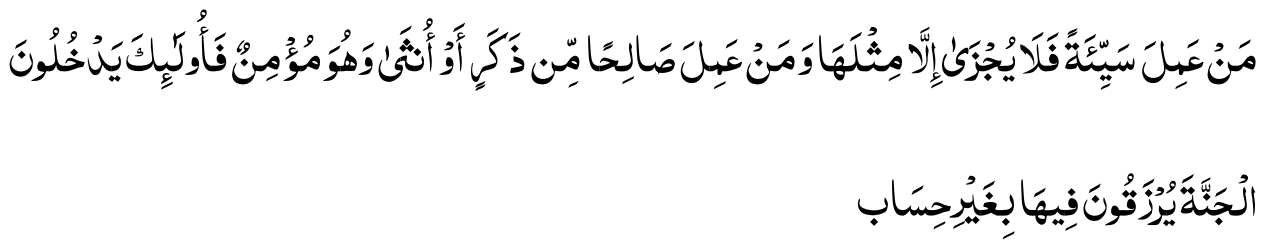

'Whoever does an evil deed will not be recompensed except by the like thereof; but whoever does righteousness, whether male or female, while he is a believer - those will enter Paradise, being given provision therein without account.'. [Ghafir, 40:40]

The Qur'an emphasizes equality between both of them regarding their rights and duties.

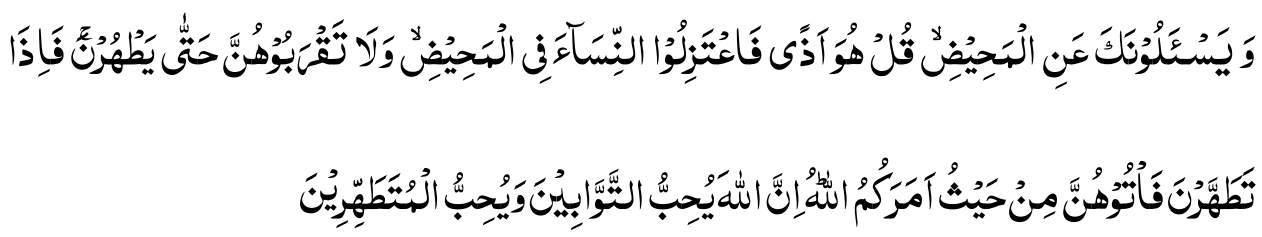

\footnotetext{
${ }^{4}$ Salwa Ismail; (September 2004); Being Muslim: Islam, Islamism and Identity Politics

${ }^{5}$ The Holy Quran 40:40
} 
The Upshots and Socio-Cultural Character for Muslim Women in Islamic Society

'...And due to the wives is similar to what is expected of them, according to what is reasonable....' [Al-Baqarah, 2:228 ${ }^{6}$

And, it says,

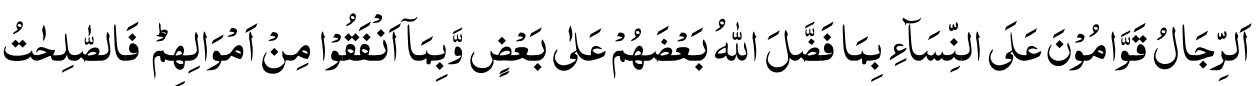

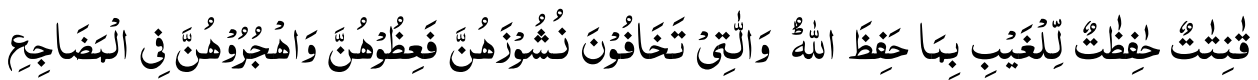

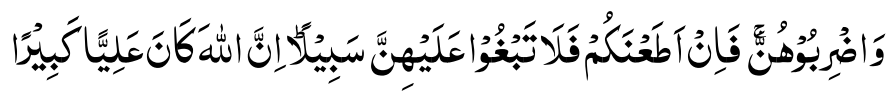

'...But if they obey you [once more], seek no means against them. Indeed, God is ever Exalted and Grand.' [An-Nisa, 4:34]

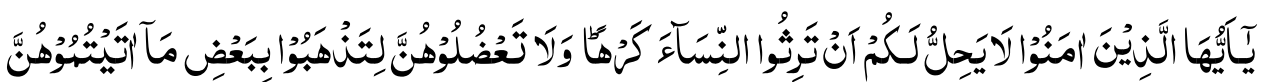

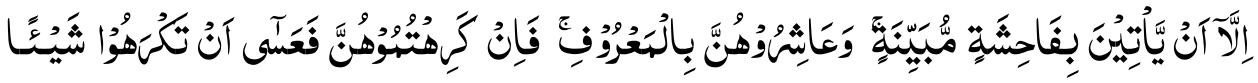

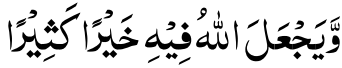

And, ' $O$ you who have believed, it is not lawful for you to inherit women by compulsion. And do not make difficulties for them in order to take [back] part of what you gave them.' [An-Nisa, 4:19]

The most perfect believers are the best in conduct and best of you are those who are best to their wives. (Ibn-Hanbal, No. $7396)^{8}$

\footnotetext{
${ }^{6}$ The Holy Quran 2:228

${ }^{7}$ The Holy Quran 4:19

${ }^{8}$ Ibn Hanbal Hadith no 7396
} 
The Upshots and Socio-Cultural Character for Muslim Women in Islamic Society

Once a man came to Prophet Muhammad (P) asking:

O Messenger of God, who among the people is the most worthy of my good company? The Prophet $(P)$ said, Your mother. The man said then who else: The Prophet $(P)$ said, Your mother. The man asked, Then who else? Only then did the Prophet $(P)$ say, Your father. (Al-Bukhari and Muslim).

A famous saying of The Prophet is "Paradise is at the feet of mothers." (In Al'Nisa'I, Ibn Majah, Ahmad).

"It is the generous (in character) who is good to women, and it is the wicked who insults them."

\section{BACKGROUND: THE LINK BETWEEN SOCIO-CULTURE AND IDENTITY IN ISLAMIC SOCIETY}

Muslim Arabs gained the interrelatedness of character and legislative issues from their pre-Islamic archetypes, for whom the character was primarily portrayed as having a spot with a faction, which was the fundamental kind of social affiliation that may openly be called sociocultural in that period. Right, when Prophet Mohammad passed on, coincidentally, there was a central government inside the Arabian Peninsula arranged in Medina and tribal characters were replaced by a united character, that is, Islamic certainty. There was, in any case, a passing period, inside the essential significant lots of Prophet Mohammad's settlement in Medina, when such award was set up inside the town. Under the Medina Charter or Șahīfat al-Madinah, such an ensured framework suggested by all factions and religions present in Medina, diverse exacting and tribal components lived separately, with a shared free 


\section{The Upshots and Socio-Cultural Character for Muslim Women in Islamic Society}

semi-socio-cultural force liable for settling and gatekeeper. It is normally said this was the fundamental time span in Islamic history when legislative issues and character were isolated, to some degree. By virtue of various events like Jewish families' organized exertion with the Meccan Quraysh, the district obscured away, and when of Prophet Mohammad's destruction, a totally fledged evangelist state was in its place. ${ }^{9}$

\section{PROHIBITING SOCIO-CULTURAL DISAGREEMENT}

After Prophet Mohammad's passing, a standard segment was combined inside the Islamic/Sunni record of legislative issues. Regardless of the way that legislative issues spared its severe ramifications as a mechanical get together for realizing Islamic standards and regardless, propelling the religion, the socio-cultural position wasn't seen as freed from terrible conduct and safe from the examination. The plan of a caliph was a twolevel selective cycle. From the start, the politico-severe supreme picked the caliph from a gaggle of instructed and only contenders; by then the overall population, generally idly, certified the game plan. Basically, in any case, the procedure, which included both severe and normal fragments, wasn't so immediate and freed from unapproved impacts. Such a record of socio-cultural position and its assurance system should have reliably allowed such a true socio-cultural contrast and subsequently the improvement of socio-cultural obstruction. Regardless, basically, this didn't happen, as can be seen inside the demonstration of a required degree of loyalty. It is normally fought that the comfortable association among

${ }^{9}$ Maydan Islamic thought; SEYED MOHAMMAD ALI TAGHAVI; (May 22, 2017); "Identity Politics, Divisions within Islam and the Need for Incorporating the Concept of Socio-cultural Dissent in Islamic Socio-cultural Culture" https://themaydan.com/2017/05/identity-politics-divisions-within-islam-needincorporating-concept-socio-cultural-dissent-islamic-socio-cultural-culture/ 


\section{The Upshots and Socio-Cultural Character for Muslim Women in Islamic Society}

character and legislative issues didn't allow the advancement of genuine socio-cultural obstruction.

"It is every now and again battled that the comfortable association among character and authoritative issues didn't allow the improvement of real socio-cultural obstruction. On the other hand, disregarding the way that investigation of the caliph was allowed, and even enabled during the age of the underlying four caliphs, in later periods it had been not persevered." This was, regardless, not bound to Muslim social requests. As referred to already, the possibility of valid socio-cultural distinction has not been seen in any overall population starting not very far in the past. The issue in Muslim social requests or any socio-cultural society maintained imparted character administrative issues, was that they prepared for the augmentation of the latest exacting characters started in socio-cultural logical inconsistency.

\section{PROLIFERATION OF DIVISIONS}

In spite of the way that there is no course of action among Muslim scientists on correctly when severe divisions rose inside Muslim society, various recorded records trademark the event of such divisions to contrasts on the issue of movement to Prophet Mohammad. The issue was of principal noteworthiness since substitutions to the Prophet were to gain the two his severe and socio-cultural position. The similar number of scientists of the over a wide range of time have watched, most parts inside Islam were achieved by contrasts on the issue of activity.

Such authoritative issues proceeded in Islamic culture incited the increase of divisions. The issue was that the close by association among character and administrative issues didn't allow such a socio-cultural inconsistency. The close-by association among religion and administrative issues offered rise to the likelihood that any socio-cultural inconsistency could similarly 


\section{The Upshots and Socio-Cultural Character for Muslim Women in Islamic Society}

be noncompliance to Islam characteristically. From now on, it had been called disruption, or fitnah, and set off the restriction and prohibiting of protesters.

"The close by association among religion and administrative issues offered rise to the likelihood that any socio-cultural distinction could moreover be disobedience to Islam intrinsically. Thusly, it had been called insubordination, or fitnah, and set off the dismissal and removal of free thinkers."

On the other hand, the protesters not simply communicated doctrinal bases for their contest, yet furthermore endeavoured to work out a particular socio-cultural society of their own. In a manner of speaking, and as of late outlined character set up during an inconsistency over the power issue was never kept to doctrinal conflicts, and certainly had a socio-cultural bend, rehashing the association among character and administrative issues. Dissenters expected to bar various Muslims doctrinally, yet furthermore deliberately. In this manner, any socio-cultural contrast was appropriate to be set in character terms, shutting the door for any trade-off, and planning for the break. ${ }^{10}$

\section{SPLITS INSIDE ISLAM}

The preeminent significant split inside Muslim society that incited the formation of a substitute association detaching itself from the remainder of Muslims was started by the party Khavari, or individuals who left the standard Muslim society. This occasion occurred in years 36 and $37 \mathrm{AH}$ (657 AD), during the experience of Siffin, between the militaries of Imam

10 "Politics, Power, and Authority | Boundless Sociology"; https://courses.lumenlearning.com/boundless-sociology/chapter/politics-powerand-authority/ 


\begin{abstract}
'Ali, the fourth Caliph, and Muawiya, the agitator legitimate top of the Levant. Right when a settlement through politeness was proposed, a gaggle of 'Ali's military wandered, enduring that no one yet God can figure out who the caliph is. This was the start of the development of degrees of progress instigating the course of action of the Khawarij.

Another division inside Muslim society was accomplished by the Sunni/Shi'a capability over the issue of the genuine development to Prophet Mohammad, which was set off after his passing. The differentiation over association wasn't only a socio-cultural irregularity, in light of the fact that the authority was needed to join the more colossal issue of the incredible bearing. Such a qualification reliably formed into a division whereby not exclusively did the parties deny each other doctrinally yet besides tried to work out explicit social solicitations under what was accepted to be the valid association. ${ }^{11}$
\end{abstract}

\title{
SCOPE OF STUDY
}

The perceptual consolidation of identity politics we see in the society today is more of a substantial part of modern state politics which dramatically changes the outcome and outlaw the assumption of gender equality among state competitive under the domain of international arena, moreover, the legislative and democratic communities of gender discipline tend to mock over the disciplinary and superficial parts played by women in politics, whether it was revolutionary movements like the women protest or feminism outcast. The Starbuck view of identity creation and

${ }^{11}$ Maydan Islamic thought; SEYED MOHAMMAD ALI TAGHAVI; (May 22, 2017); "Identity Politics, Divisions within Islam and the Need for Incorporating the Concept of Socio-cultural Dissent in Islamic Socio-cultural Culture" https://themaydan.com/2017/05/identity-politics-divisions-within-islam-needincorporating-concept-socio-cultural-dissent-islamic-socio-cultural-culture/ 
overlapping barrier in the conventional ladies' participation alongside with men in various enchanted and entangled ways. From the creation of tribes till the ongoing globalization of the Islamic society economy and fragmentation of state in a substantive level of classes. the aspect of politics has turned in to a new leave pronounced has many as a class struggle or enslavement of one identity over another identity in order to showcase their supremacy and verdicts.

\section{PROBLEM OF ANALYSIS:}

Identity is something that makes you different among the other entities you wander with and it is the same scenario with state until and unless a state is recognized or better yet identified it can't conduct any formal interaction or relation and sometime these identities are used to gain sociocultural games and racial conflict on the other hand some time these identical difference also reflects the policy emerged at the state just take Lebanon for example it ruled by four religious entities having different identities and apart from that the two majority are Muslim majority like Shia and Sunni, and third is Christianity by identities but these entities use their identities to overcome policies to rule state and socio-cultural identities have different forms like sectarianism, Hinduism, whites, and blacks and some are used as a concept to jeopardize a state affair our religious identities as we see in the form of Islamization or even in history politics of often use by religious authority to rule a state affair like the period of the reformation, and due to these concept politics interrelates identities and manipulate minorities. Socio-cultural identities are crucial for conducting state relation and affairs of course but often in the eye of national interest state often use these identities or concept as a sociocultural tool. 
The article in accordance with the variant of the subject of the topic will be based on the theory of three levels of analysis, global emphasizing social class analysis emphasizes the socio-cultural power of capitalist elites. It is often split into two parts. One is that the 'power structure' or 'instrumentalist' approach; the opposite is that the 'structuralism' approach. the facility structure approach focuses on determining who rules, while the structuralism approach emphasizes the way capitalism operates, allowing and inspiring the state to try to some things but not others the impact on women by socio-cultural influence and discriminating biases swung by the motion of their identity overstates domestic and foreign policies, state analysis emphasizing over identity cosplay of women in different critics in the society

\section{RESEARCH OBJECTIVE AND CONFLICT OF INTEREST:}

1. To discover the pertinent purposes behind the presence of personality governmental issues and imbalance among ladies in the west and Islamic state.

2. To discover critical jobs played by ladies in summing up cooperation in legislative issues.

3. What are the perspectives on various socio-cultural specialists about ladies' investment in legislative issues?

4. What are the pretended by ladies and another legislative capacity to guarantee sexual orientation correspondence among ladies in governmental issues?

5. To discover huge arrangements of the UN contract and joined country association will be talked about.

The article will be shown through the data gave by auxiliary asset and it will decide the criticalness of ladies in the socio-cultural ground 
inside states alongside the preliminary and indictments they face in current occasions.

\section{LITERATURE REVIEW:}

\section{WHAT IS POLITICS OF IDENTITY?}

As indicated by C. Calhoun (2001) Socio-cultural character dependent on essential plunge, language, or culture are depicted as 'ethnonationalism'. Ethno patriotism is extensive in serious Islamic society. Notwithstanding the way that nationalists' conviction frameworks regularly present ethnic solidarities basically as obtained, social specialists generally separate them as indications of philosophical and socio-cultural planning. Conversations remain dynamic concerning how much ethnic intelligence explains energy and concerning the aspect of the state as the fixation or wellspring of nationalism. Ethno patriotism is generally stood apart to metropolitan enthusiasm from the last addressing deliberate assimilation into a sociocultural organization. In some irregular case what makes a difference is one of degree, not complete opposition. ${ }^{12}$

${ }^{[8,9]}$ In Merriam Webster as to Orlando Peterson socio-cultural character means" authoritative issues during which get-togethers of individuals having a specific racial, severe, ethnic, social, or social character will as a rule market their own specific preferences or stresses without reference to the charges or stresses of any greater socio-cultural get-together". ${ }^{13}$

Character authoritative issues took its serious structure during the last half of the main outstanding century. It created as an emancipatory technique

12 Science direct; C Calhoun, (2001); "Socio-cultural identity, Ethnonationalism: Cultural Concerns". https://www.sciencedirect.com/topics/computer-science/socio-cultural-identity ${ }_{13}$ Orlando Patterson; Merriam Webster, socio-cultural identity definition; https://www.merriam-webster.com/dictionary/identity\%20politics 
for a socio-cultural movement and thinking maintained the common experience of treachery by explicit get-togethers-strikingly blacks, women, gays, Latinos and American Indians. ${ }^{14}$

${ }^{[10]}$ According to Bobbi privileged in her chronicle of socio-cultural character: character, measure, verification circulated in (January 2018) proposed the certified essentialness of character authoritative issues has followed "Personality shapes different perspectives of life, from how we see the Islamic society to how we lift on. The possibility of a sociocultural character can best be jumped on as an internal story of one's sociocultural self. Character is just the story that we tell and others nearly what our personality is, the thing that our character was, and whom we envision ourselves to be. ${ }^{15}$

\section{SOCIO-CULTURAL IDENTITY OVERVIEWED BY HISTORIAN AND SCHOLAR IN HISTORY}

Character legislative issues in present-day governmental issues is a lot of ethnical and individual part of philanthropic living that raise country state towards the asked of numerous trick from the medieval times, where Bible was a wellspring of personality control between the popes and worker to the foundation of the socialist and liberal viewpoint of contention, the

${ }^{14}$ FABRIZIO BERNARDI, JUAN J. GONZÁLEZ, MIGUEL REQUENA ; "THE SOCIOLOGY OF SOCIAL STRUCTURE" Universidad Nacional de Education a Distance, Spain; https://www.researchgate.net/profile/Fabrizio_Bernardi3/publication/310912518 THE_SOCIOLOGY_OF_SOCIAL_STRUCTURE/links/583ad9e508aef00f3bfd3 bc2/THE-SOCIOLOGY-OF-SOCIAL-STRUCTURE.pdf

${ }^{15}$ Bobbi Gentry; (January 2018). "Socio-cultural Identity: Meaning, Measures, and Evidence" https://www.researchgate.net/publication/321484462_Sociocultural_Identity_Meaning_Measures_and_Evidence 
character has been the other way around in wiping out helpful rights particularly of females leads of the antiquarian time.

Besides, a scholar from pragmatist and liberal way of thinking have examined it a hotline of battles among liberal and the pragmatist state as far as governmental issues, financial aspects, religion, common freedom and numerous different appalling unauthenticated written work and cosplay between state, in this setting, we will zero in on Marxist perspective on character legislative issues. ${ }^{16}$

Karl Marx's duty to the socio-cultural character has its own noteworthiness and wide conviction frameworks. Considered in (1818_ 1883) a scientist of the communist announcement close by a scholar Frederic Engle's built up a perspective of class and character legislative issues that still indisputable today. Marx is striking for his responsibility in the class fight between the bourgeoisie and the common labourers in the overall population censuring the liberal and neo-liberal possibility of the free venture and the precarious arranged method of mainstream government over communist conviction framework The Communist Manifesto in 1848; further not far-removed, he made Das Capital (the fundamental volume was appropriated in Berlin in 1867; the second and third volumes were scattered after death in 1885 and 1894, independently), which examined the working theory of colossal worth. ${ }^{17}$

${ }^{16}$ WILL KENTON; BRIAN BARNIER; Investopedia, (May, 5, 2020).” Karl Marx. https://www.investopedia.com/terms/k/karl-marx.asp

${ }^{17}$ Government and the State; Marxist theory; https://courses.lumenlearning.com/boundless-sociology/chapter/government-andthe-state/ 
The emergency of free undertaking (private venture) has uncovered some critical orchestrated movements of insurance from the current society, its attributes, its ethical quality and its frightening vile acts and abuse. The focal inconsistency in the public eye remains the obstruction between wage work and capital. In any case, misuse takes various structures, some of them basically more settled and more noteworthy developed than wage enslavement.

Among the most and anguishing sorts of misuse is the abuse of ladies in a male-controlled Islamic society. The hindrance of ladies against this immense persecution is of principal vitality in the battle for communist disturbance, which can't be refined without the full support of ladies in the battle against free endeavour. For a huge time length the quality of class society has built up a strong explanation behind assistance in the family: figuratively speaking, on the oppression of ladies to men. Such intimidation is unquestionably more settled than private endeavour, as Engels clarified, the improvement of the male-driven family addresses the "Islamic society surprising whipping of the female sex. The man took demand in the home comparably; the lady was ruined and lessened to oppression, she changed into the prisoner of his yearning and a direct instrument for the creation of youngsters." This male control and the predictable condition of ladies in the public field and the family is eventually being tended to, near to the diverse savage affiliations that we have picked up from an earlier time. For what reason should ladies keep persisting through the situation of labourers? The exploring of the limit of ladies in the public eye and the family has credible reformist ramifications and can incite a reformist tending to of business visionary society itself. The slight degeneration of free endeavour prompts a genuine weakening of 
the states considering everything. All things considered, it controls especially savage conditions on ladies and teenagers.

The degeneration of business visionary society uncovers itself in its crudest structure in the plague of violence against ladies. In India, Pakistan, Argentina, Mexico and different nations, this has, comparative stuns are being executed against ladies and kids. These are revolting consequences of the ailment of a general populace that is destroyed arranged for cut down. ${ }^{18}$

\section{FEMINISM AND SOCIO-CULTURAL IDENTITY}

Lady's privileges is a social and total character that is a puzzling union of socio-cultural and individual conviction frameworks (Zucker and BayCheng, 2010). People who recognize as ladies' extremist offer a sentiment of amicability and organization that goes with a social turn of events, which "incorporates the people who believe sexual direction to be a huge order of assessment, who researches female hindrance, and who work to improve women's situation".

[16] One of the pre-prominent fruitful acclaimed and most noteworthy socio-cultural witticisms of the chief Women's Liberation Movement at extends that I adjusted be stressed at ranges the middle Nineteen Sixties stated that "the individual is socio-cultural." That articulation was honed in light of fights at traverses the Nineteen Sixties social advancements out of that the Women's Liberation Movement starting rose. It got the information that a great deal of what was accepted to be near and dear

${ }^{18}$ In Defense of Marxism; (28, September 2018); "Marxism Vs Socio-cultural identity. https://www.marxist.com/marxist-theory-and-the-struggle-against-alienclass-ideas.htm 
issues had social and socio-cultural causes, were widely shared among ladies, and may solely be settled by social and socio-cultural correction. ${ }^{19}$

During the 1960s social turns of events - the Civil Rights Movement, the advancement against the War in Vietnam, and thusly the analyst improvement which soaked more understudy rights and dynamic power on school grounds - women were central performers. At time frames advancements, regardless, ladies activists were denied the predominance and consequently the obligation that they defended that they'd achieved. Disregarding their obligation and duties, they were regularly declined organization positions, treated as second arrangement voters, encouraged to make low, and set on a show as sex objects. By the centre, the Nineteen Sixties a couple of those ladies began to react to and organize around the extreme legitimate irregularity at extends social improvements that struggled for confidence and balance and denied these proportional basic rights at ranges their own positions. Beginning at extends the social uniformity improvement, with a blessing made by The Virgin King and Casey Hayden, and rapidly later on and extra normally at ranges the mission, SDS, and elective social turns of events, ladies progressives began to demand worth and view as activists.

The reaction of their male and elegant partners appears to be unpreventable taking everything into account, in any case, was faltering and unsettling by then. Women's cases were met with disdain, mock, and accordingly, the socio-cultural dispute that they were pushing concerning

19 Springer link encyclopedia; Diana Perry; "Feminist identity" https://link.springer.com/referenceworkentry/10.1007\%2F978-94-007-0753$\underline{5 \quad 1036}$ 
"singular" issues and through this way weakening advancement feasibility in fighting the "socio-cultural" dishonourable demonstrations of fanaticism and expansionism. At any rate, ladies be as such ravenous, it had been asked, to zero in on their own discontent once dull individuals were denied choice advantages in Mississippi, workers were being napalmed in Vietnam, and understudies were treated as numbers in goliath common government authority's universities.

The socio-cultural examination basic this vision of non-public fulfilment declared that finish of the inclination that invaded socio-cultural and social institutional blueprints and viewpoints was the sole strategies for guaranteeing that everybody, paying little mind to sex, would be able to rehearse singular adaptability.

The social and socio-cultural changes set up by the principal women's improvement along these lines were at ranges the organization of a sexunbiased model of society. In this, every individual would be overseen accomplice social uniformity to shape her or his own life paying little heed to sex. The idea of sex separation was deemphasized by an advancement zeroed in on correspondence, as ladies looked after to understand the option to totally take an enthusiasm completely parts of society. Assortments among ladies and men, that had proficiently been a central sane and direct segment of limiting ladies to an alternate standard "refined" circle, came defenceless. The non-public reality of one's sex became accomplice field of the socio-cultural fight, as growing amounts of ladies' activists tried the general way of thinking that sex and sex were genuine prerequisites on the privilege to confidence. The socio-cultural value mentioned that sex create no separation. Wants were high that 
women would overcome the opportunity that that that they had been dismissed that inclination would be squashed. ${ }^{20}$

The country overall transformed into additional moderate far and away zones of socio-cultural life, due to one side, with Chief Executive as its common transporter, dispatched what Susan Faludi has referred to as a "Response" against the reformist changes of the previous numerous years. Due to the augmentations of the women's advancement began to slow, a couple of ladies' activists got crippled with the continuation of bullhead points of view and lead. The gap between compensation for women and men restricted at any rate remained steadily consistent, untimely inheritances came underneath revived attack, and thoughtfulness regarding and concern concerning the level of goading and violence against ladies extended. This last amusingly mirrored the Women's Movement's past accomplishment, for attributable to its undertakings direct earlier thought regarding by law straightforward, like harassing at work or wedding and attack, was denounced, and extended updates on ruthlessness occurred. without a doubt, creating amounts of ladies wound up doing what Arlie Hoch youth has implied as to the "Second Shift" - working at all day occupations for the term of the day and a subsequent action gathering as they continuing to anticipate most or the aggregate of the heaviness of home and youngster care in their families. Finally, however, the Nineteen Seventies were the blossom of the Movement, extending amounts of youngsters by then were being raised in neediness as a result of their single guardians' past mates or dears contributed nothing to support them,

\footnotetext{
${ }^{20}$ Stephen Mcglinchey, Rosie Walters \& Christian Scheinpflug; "International Relation Theory"
} 
were changing into distressingly looked at the perils of abuse, attack, and incitement, and were dampened by their mothers fights with the twofold weight of work and family care. As these women formed into adolescents at extends the Eighties, a couple were dispensed with from convinced that the women's improvement had liberated anybody. Those issues affecting women saw to fly inside the substance of lady's privileges' certifications and wants for reasonableness, and a few women, crippled with the development of progress and subsequently the assurance of predisposition, reacted by pulling back from claims for value and from demands for social adjustment.

However, in view of the Eighties progressed, it had been not only ladies' activists Islamic society Health Organization were experiencing upsetting and extending negativity. In a period once the moderate legislative issues of Reagans were transcendent, the hardship was that no persuading diverse reformist Islamic society-see was being made. A fantasy of an overall population of fairness and value wasn't offered to counter the moderate sort of government, related in this way the satisfaction of a libertarian culture appeared less and less conceivable. ${ }^{21}$

\section{TYPES OF SOCIO-CULTURAL FEMINISM AND SOCIO- CULTURAL THEORIES}

In the event that everybody men are brought into the planet free, how could it's that everybody ladies are viewed as slaves" -

${ }^{21}$ Joan D. Mandle; Associate Professor of Sociology; Colgate University; "How Socio-cultural is the Personal? Identity Politics, Feminism and Social Change"https://userpages.umbc.edu/ korenman/wmst/identity_pol.html 
Lady's privileges recommend a technique for felt that is worried over the state of adolescents in the public field, the explanations for their sadness and along these lines the measures for reestablishing their due circumstance, with a genuine proposition in respect, effect and riches. Women's lobbyist socio-cultural course demands renaming the personality of the 'socio-cultural' with the top goal of recalling the relationship among people for society inside the space of 'socio-cultural'. Inside the past, administrative issues were worried over the development of intensity inside everybody circle; the working environment practised by men over ladies in neighbourhood circle, work-spot, school or road was sidestepped from its space since it had a district with the non-open field. Women's activists fight that this division among 'open' and 'private' impelled a demolished perspective on a socio-cultural course which must be changed now. Women's opportunity holds that ladies have endured are so far enduring unfairness by virtue of their sex; henceforth it's for persuading measures for the redressal of that bad form. There are different translations in women's lobbyist believed beginning from different strands to be express: Liberal, Marxist/Socialist, Radical, Post-Modernists, PostColonialists, Feminist Constructivism.

\section{DISCUSSIONS INSIDE FEMINISM}

Rosemary Tong has demonstrated a critical solicitation which isolated women's fanatic idea in the going with six strands or groupings especially liberal woman's benefits, progressive women's opportunity, Marxist and communist woman's benefits, postmodern women's opportunity, women's 
lobbyist constructivism, post-boondocks ladies' freedom and women's protester fundamental theory. ${ }^{22}$

\section{1) LIBERAL FEMINISM-}

Liberal women's opportunity tends to the central brief model in women's protester thought. It looks for development inside the state of youths in the likeness of the strategy of reformism. The Liberal woman's benefits are moreover worried over indistinguishable rights for the 2 people, for which ladies discovered the chance to be secured and can incorporate a comparative part inside the public field and have a comparable limit in managerial issues likewise as beating interminably. The liberal women's lobbyist thought was first imparted inside the eighteenth century Europe by most women's radical minds" Olympia de Gorges" and followed by Wollstonecraft from Britain. The French Philosopher Simone de Beauvoir additionally incorporates a spot with the Liberal women's lobbyist viewpoint. The Liberal ladies' activists have fought that as an inevitable result of the varied example of socialization and unreasonable social and social practices ladies were supervised less open entryways than men to understand their most noteworthy breaking point as individuals. As a postponed result of which, women had been restricted to home to pursue nearby associations and had negligible chance to practice their scholarly resources or make limits close by those of neighbourhood commitments.

\footnotetext{
${ }^{22}$ Nitic Yadav; University of Delhi Graduate Student; "Feminism and the Politics of Interpretation" https://www.academia.edu/37809709/Feminism_and_the_Politics_of_Interpretati on
} 
The Scholar Islamic Academic Research Journal

Vol. 6, No. 1 || January-June 2020 || P. 304-252

https://doi.org/10.29370/siarj/issue10aren21

The objective of Liberal women's opportunity is to guarantee supreme sexual course correspondence among individuals. ${ }^{23}$

\section{2) MARXIST AND SOCIALIST FEMINISM-}

The Marxist women's projects what's more censures liberal perspectives which underline on the overall maltreatment of adolescents by men. They see the maltreatment of adolescents not as a possible result of inclination or carelessness or conscious development of individuals yet as an outcome of the grouping framework under Capitalism. The reason of Marxist women's opportunity is seen inside made by Frederick Engel's work 'the inception of the Family, Private Property and hence the State' (1884), where he guaranteed that ladies 'misuse began inside the presentation of individual property which incited a standard split between 'general society' and fittingly the 'private' district. The vibes of industrialization and individual undertaking made creation as the universe of chance since it had been inside the 'open' space; while ladies came to be found considering the way that the individual property of men and were limited to the home. The Marxist women's lobbyist revolved around the envisioned by ladies in furnishing market economy with a significant 'hold enormous number' of work which could comparatively be manhandled from time to time off work inadequacies or used to keep male work humble. The Socialist woman's benefits have seen that the abuse of adolescents had happened from the pre-industrialist social demands and has proceeded to the communist social solicitations. Notwithstanding, they

23 Elisabeth Armstrong; (2020); "Marxist and Socialist Feminism" Smith College,

https://scholarworks.smith.edu/cgi/viewcontent.cgi?article=1014\&context=swg f acpubs 
The Scholar Islamic Academic Research Journal

Vol. 6, No. 1 || January-June 2020 || P. 304-252

https://doi.org/10.29370/siarj/issue10aren21

shifted from the Marxist woman's benefits as they presented a second focal material explanation behind the clashing treatment of youths. That is the individual driven game-plan of male quality and private endeavour is that the essential oppressor. ${ }^{24}$

\section{3) RADICAL FEMINISM-}

Radical Feminism zeroed in on the need to make up a 'ladies centred' appraisal as an approach to managing challenging all male-depicted structures and attributes. They are upbraiding of both the liberal and Marxist woman's benefits as they consider both to offer a model of ladies' chance which relies upon male attributes, subsequently promising them to make progress toward what is basically man driven qualities. This is regularly typically in light of the fact that the novel women's dissenter sees the base of ladies' maltreatment not as a by - delayed consequences of the market economy yet rather inside the social game plan of male-controlled society. The epic women's activists were the major to correct what's presently generally found considering the way that the focal data on women's nonconformist idea: individual is socio-cultural". It offers the character that what's necessary isn't just ladies' chance to work it out appropriate correspondence; acceptance to open space and procedures for creation yet likewise fuses a cautious change inside the head private and agreeable circles of human associations. ${ }^{25}$

\section{4) POST-MODERNIST FEMINISM-}

\footnotetext{
24 MARXISM AND RADICAL FEMINISM; "FLASH CARD FACTS". http://www.sociology.org.uk/notes/revision_card_theory2.pdf

25 Denise Thompson; " $\mathrm{R}$ a di $\mathrm{c}$ al Femi in sum to $\mathrm{d}$ a $\mathrm{y}$ " https://literariness.org/wp-content/uploads/2020/04/Denise-Thompson-RadicalFeminism-Today-2001-SAGE-Publications-Ltd.pdf
} 
It's a women's radical hypothesis that goes with post-present day and poststructuralism theory, trusting itself to be moving past the trailblazer polarities of liberal women's opportunity and progressive woman's benefits. Charlotte Hooper's book 'Masculine States (2001) is an example of post-current printed appraisal during which she made that regulatory issues can't be seen beside if we value the ramifications of the very actuality that it's coordinated by and large by men. Also, Lela Gandhi points out, the foundations of the post-colonial nation-state lie at the moment when a general consensus is established between anti-colonial nationalism and European imperialism. Managerial issues shape men the vital remarkable total as men shape authoritative issues. ${ }^{26}$

\section{5) POST-COLONIAL FEMINISM-}

The most question of the Post-Colonial women's radical is that ladies' compulsion must be seen differentially inside the setting of the going with experts like race, class and topographical locale. Reliable with this school of the figure, all that ladies need to be seen on the grounds that the heads as opposed to misfortunes. For example, a bit of the standard exhibits of adolescents like wearing scarves is regularly observed by the west as being in reverse and upsetting. Thusly compelling western rules could be seen as being devouring yet additionally could lead on to clashes inside the overall population. The post-outskirts ladies' dissident essayists like Chandra Mohan had recommended that ladies' pressure must be gone to inside their own social setting, instead of through a few extensive discernment of

${ }^{26}$ Carolina Matos; October 2015, "Postmodernism, equality and feminism: current contemporary issues. DOI: 10.13140/RG.2.1.2853.5761 file:///C:/Users/admin/Downloads/Salamancapaper.pdf 
ladies' needs. She has censured western women's dissenter's depiction of Third Islamic society ladies as poor, ignorant, overwhelmed and weakened in office. $^{27}$

\section{6) FEMINIST CONSTRUCTIVISM-}

Women's fanatic constructivism as an Islamic society relations speculation develops the likelihood of constructivism, which is an epistemological framework that makes information and significance through human affiliation and thoughts. Elisabeth Pregl has produced using the disposition out of women's nonconformist constructivist in "The Global Construction of Gender "(1999). During this book, MS Pregl has battled that sex legislative issues have amassed Islamic society definitive issues which have impelled the social gathering of etymologically set up rules as for how states collaborate with one another and with their own tenants. Pregl has shown how contemplations with respect to ladies' dissident have added to the discussion in normalizing privately arranged work done by ladies inside the general association. The low wages and weak working conditions are regularly maintained on grounds that privately settled work isn't 'genuine work' as these works are done inside the private regenerative float of searched after based creation.

\section{WOMAN'S BENEFITS AND METHOD}

(1994) zeroed in on the distinctive way how sex was being seen additional time since it acknowledges the vibe states of people and their relationship with each other. The change inside the hugeness of sex impacts affected

\footnotetext{
${ }^{27}$ Swati Parashar; 28 Jun 2017. "Feminism and Post-colonialism: (En) gendering Encounters" https://www.tandfonline.com/doi/full/10.1080/13688790.2016.1317388
} 
everyone establishment's overall public methodologies at various events in their arrangement of encounters. Many battles that we've seemed a post women's radical period and woman's benefits have declined in its activity and noteworthiness. Regardless of women's activists like Sylvia Wall's by in her book, 'The Future of Feminism'

Insistently states that a woman's benefits are throbbing and taking new structures. It will remain to fit as long as sexual heading uniqueness and man-controlled society drive forward. Actually, new ladies' lobbyist encounters are looking out for neighbourhood issues, forming generally speaking associations and that speak to extensive expert incomplete ${ }^{. .28}$

\section{EUROPEAN ASSUMPTION OF SOCIO-CULTURAL IDENTITY}

The rise across Europe of philosophical gatherings grasping an ethnic start of the state, unequivocally restricting to the pioneers and minorities and their cases to have a spot, has brought into clear assistance the executive problems with character (Person, Vignola's, and Brown 2009; Hopkins 2010; Huddy 2001). In equivalent, stresses with the failure of multiculturalism and compromise have problematized what proportion minorities see with their ethnic 'roots' as a choice than with public characteristics (Koopmans 2013; Cameron 2011; Reskins and Wright 2013). Speculation and current composing sets that such streams could be foreseen to influence the larger part people's social characters (Tajfel and Turner 1986; Beaux et al. 1995), as they respond socio-culturally to the unequivocal planning of accounts of ethnic distinctive verification (Kenny

\footnotetext{
${ }^{28}$ Nitic Yadav; University of Delhi Graduate Student; "Feminism and the Politics of Interpretation". https://www.academia.edu/37809709/Feminism and the Politics of Interpretati on
} 
2014). Note that through socio-cultural character, we propose the striking nature of administrative issues to a person's understanding of self, as a substitute than partisanship. These contemporary enhancements would similarly be foreseen to shape the ethnic and socio-cultural unmistakable evidence of minorities because the striking idea of minority reputation is raised and politicized through such records.

The enduring question has developed the immensity of socio-cultural heading and ethnonational ID for predominant part group rehearses, as an example, merriment enlistment or projecting a polling form 'Leave' within the progressing UK decision (for instance Henderson et al. 2017). Sociocultural duty has besides been related to ethnicity and to minority group experiences (Sanders ET al.2014). There's additionally some confirmation that those with definite socio-cultural partisanship have more grounded ethnic characters (Nandi and Platt 2015). Regardless, present assessment has not, now thus far saw whether the drivers of all the more appealing socio-cultural character are furthermore the drivers of an overhauled ethnic character. That is, whether or not ethnic and socio-cultural characters are co-chosen. This is often our responsibility.

\section{MINORITY SOCIO-CULTURAL IDENTITIES}

With regards to developing minority ethnic populaces in Europe, there are clear discussions on multiculturalism, assimilation, and absorption both inside the scholastic Sphere and therefore the socio-cultural region (for example Koopmans 2013; Mood 2007; Brubaker 2001).

The socio-cultural talk has connected fiascos of 'mix' to minority ethnic groups 'Retention of their ethnic recognizable proof and inability to collaborate with countrywide character (Cameron 2011; DHCLG 2018). As a result, extraordinary scholarly investigations have planned to verify such cases. This writing has investigated the degree, connects and results 
of the ethnic and nationwide ID of ethnic minorities from every settler and second ages (Constant, Gataullina, and Zimmermann 2009; Manning and Roy 2010; Platt 2014; Van Heelsum and Koomen 2016; Platt 2014; Nandi and Platt2015; Nguyen and Benet-Martínez 2013; Diehl and Schnell 2006; Karlsen and Nazroo2013). This writing has checked that ethnic characters tend to decay across ages, despite the very fact that in any case staying durable into the $2 \mathrm{~d}$ age, while nationwide personality increments. It's additionally shown a scope of attributes related to ethnic character, including age, sex, scholastic capabilities, occupation, a zone of home, and socio-cultural alliance.

There is tremendous verification that minority personalities are connected with kinds of socio-cultural commitment or practices. As an example, Martinovic and Verkuyten (2014) recommend that twin ethnic-public personality lessens socio-cultural commitment while every Simon and Grabow (2010) and Fischer-Neumann (2014) fined the inverse. Sanders et al. (2014) show that each ethnic embeddedness and dominant part assimilation are connected with more prominent socio-cultural commitment among minorities. Naturalization, which may be perceived as an excellent interest in objective global areas has also been connected, however not reliably, to the socio-cultural commitment of minorities (Hain Mueller, Hangartner, and Pietrantuono 2015; Street 2017).

The writing has furthermore caused to note the capacity of socio-cultural talk and nearby setting in moulding (double) personality articulation (Ahmad and Evergeti 2010; Nandi and Platt 2016; Diehl, FischerNeumann, and Mühlau 2016). Simon and Grabow (2010) as an example spotlight the politicized idea of minority ethnic personality. Exploration likewise proposes that these settings which cultivate ethnic distinguishing proof and having an area also can prepare minorities' socio-cultural insight 
(Jacobs and Tillie 2004; Sanders et al. 2014; Sobolewska et al. 2015; Hainmueller, Hangartner, and Pietrantuono 2015).

We may, consequently, accept that minorities' focus of their nationality as striking ('ethnic social character') to travel inseparably with the cognizance of governmental issues as a basic personality space ('socio-cultural social personality'). Nonetheless, we'd like observational evidence on whether. ${ }^{29}$

\section{MAJORITY OF SOCIO-CULTURAL IDENTITIES}

The greater a part of socio-cultural characters, but, have consistently within the past been normalized or disregarded in examinations of ethnic character, with identity probably being the hold of minorities (Fenton and Mann 2011). Regardless, a flourishing assortment of inquiry immediately unequivocally barbecues the lion's offer or neighbourhood masses' ethnic character. This composing suggests that ethnic separating verification among the larger part is more delicate than among minorities, yet but is even more intelligently remarkable (Nandi and Platt 2015, 2016). That is, it comes into lightening under uncommon accessible, short-lived, and socio-cultural conditions (Kenny 2014). Contemporary English character enunciation has been related to a selected 'sentiment of the nation' (Bond 2017; Leddy-Owen 2014; Kumar 2003); and across Europe, we see that public characters are being reconceived. rather than metropolitan advancements of nationhood (Smith 1991), the ethnic establishments of race characters (Wimmer and Glick Shiller 2003) show up at finding growing enunciation inside the related exercises in countries, as an example, Austria, Denmark, France, Germany, Greece, Hungary,

${ }^{29}$ Alita Nandi and Lucinda Platt; (2018); "The relationship between sociocultural and ethnic identity among UK ethnic minority and majority populations". http://eprints.lse.ac.uk/91132/1/Platt The-relationship-between.pdf 
Netherlands, and therefore the UK with watching proposals for altruistic love and solidarity (Reeskens and Wright 2013) and threatening to labourer predisposition (Pehrson, Vignoles, and Brown 2009). Huntington's (1993) claims about social clash have watched resonation within the socio-cultural power from multiculturalism (Koopmans 2013), and public points of view have shown confidence within the incongruence of shared characters in multicultural social requests (for instance Duffy and Frere-Smith 2014).

In the UK, philosophical gatherings have expected to amass such ethnic enthusiasm through interfacing Ethnic and socio-cultural character unequivocally among lion's offer (white) people. The climb of the counter movement UK Independence Party (UKIP) within the years up to 2016 was included explicitly working of a public character, related to wistfulness for an imagined past of ordinary characteristics and sureness, which called express social understandings of Englishness (Kumar 2003). Such systems appeared to pay off in representative terms, with Englishness certainly entangled within the progressing 'Brexit' vote (Henderson et al.2017), and regard for ethnic distinctive confirmation among the lion's offer (white) masses are connected with explicit kinds of socio-cultural mindfulness, at any rate, there's on the brink of no correct evidence of this co-improvement. Without a doubt, the present assessment recommends that there's no essential association between white predominant parts' inclination of the striking quality of their character (and antagonistic to the outcast idea) and their socio-cultural groundwork (for instance Thomas et al. 2018; Duffy and Frere-Smith 2014). Or but perhaps, socio-cultural obligation and ethnic course enter complex procedures (Kenny 2014). It, likewise, stays hospitable check out whether 
similar Variables are involved in predominant part ethnic and sociocultural distinctive confirmation. ${ }^{30}$

\section{AMERICAN CULTURE OVER WOMEN IDENTITY}

In the United States, female and people constantly contrast in their vote choice, celebration recognizing confirmation, and incorporation tendencies. These qualifications, ordinarily insinuated as sexual direction gaps, have existed for a long while - in any occasion in observing that 1980 for vote need and ahead of time for some procedure viewpoints. Such gaps contain youngsters slanting extra liberal than men, with a female being more essential inclined to rule for Democratic contenders, identify with that social occasion, and take the liberal point on various consideration issues.

Regardless of the way that sexual direction openings waver contingent upon the socio-cultural choice or the consideration district, they often reach out from four to fourteen-degree centres. For example, the sex hole in 2016 official vote tendency used to be thirteen offer centres, with $54 \%$ of youngsters helping Hillary Clinton instead of $41 \%$ of men. Since women makeup half of everybody and have been more critical possibly to project a polling form in current official choices, even subtle sexual direction assortments are socio-culturally profound and interesting.

\section{OTHE EMERGENCE AND ROOTS OF THE GENDER GAP}

Many peg the foundation of the articulation "sexual direction gap" to the 1980 official socio-cultural race when the news media started the usage of that articulation to insinuate women's greater tendency to rule for Jimmy

\footnotetext{
30 "GENDER POLITICS, UNITED NATION "https://www.un.org/en/sections/issues-depth/gender-equality/
} 
Carter. Vote based candidate Carter won guide from $45 \%$ of ladies residents versus $36 \%$ of men - a nine-factor sexual direction gap. This statement has been examined because "sex" is used as a choice than "sex." But pros didn't, now advance the term and many battles in any opposition that the hole is grounded in sex wants and women's experiences and socialization.

\section{OEXPLAINING GENDER DIFFERENCES IN VOTE CHOICE AND PARTY IDENTIFICATION}

Again, most masters feature the 1980 official socio-cultural race as the advancement of the sexual direction hole in vote tendency with women from that consider turning enterprisingly additional more than likely than men to rule for the Democratic official picked one. A sex hole in birthday festivity separating confirmation recently regarded in 1968, in any case, was once now not present in 1970. It returned in 1972 and has experienced that point forward.

A couple of researchers have found verification that these openings are extra the outcome of men's development away from the Democratic Party than of women's development towards that party. Specifically, white men in the North and South host moved away from the Democratic Gathering, with white southern people moving at a snappier rate than those in the North. Late inquiry nearly recommends that ladies have stayed with or been pulled in to the Democratic Party for significant perspectives -, for instance, the sexual direction make-up of the social occasions' Congressional tasks; ladies decided for Congress is by and large Democrats.

\section{GENDER DIFFERENCES IN PUBLIC OPINION}

Differentiations among women and people on issues add to the sexual direction hole in projecting a polling form. In genuine generations, when 
researchers acknowledge that women experience comparable trouble tendencies as men, the ordinary sexual direction hole in vote anticipating essentially reduces. In actuality, colossal sex openings exist on main issues of dispute:

Attitudes about military weight show a sexual direction opening of eight to 12-degree centres overall, with female less solid of military interventions, for instance, the battles in Iraq and Afghanistan. On local force issues, ladies are less solid of the shrivelling discipline and all the more consistent gun control.

Women outright persistently more assistance for government tasks to help the considerably less fortunate and grant for regularly happening government help. Starting late, this sex hole has floated cycle ten-degree centres. Women, for example, report more raised degrees of underwriting for the Affordable Care Act.

Other sexual direction gaps are humbler. Women are unsure than people to require the approval of wed Jane and all the more consistent of gay rights. Sex contrasts on the natural components are unassuming, with female demonstrating more imperative test and help for environmental protections.

\section{APPEALING TO WOMEN IN THE ELECTORATE}

During progressing official races, the information media and socio-cultural missions have been fascinated with the socio-cultural leanings of sure subgroups of women, for instance, "soccer moms" or "security moms." But social specialists have discovered quite recently obliged confirmation of extraordinary and socio-culturally significant leanings for such subgroups of women.

Even more extensively, campaigns and socio-cultural events have made gendered pictures. The 2012 "Battle on Women" is essentially one model, 
with Democrats featuring security approaches they communicated demonstrated Republican inclination as opposed to women's benefits and cash related prerequisites. Despite genuine sexual direction openings of a collection of sizes, the present U.S. socio-cultural events and contenders need to keep up at the head of the need list that women, like men, are some acceptable ways from a strong balloting coalition. Past sexual direction, resident picks are influenced through various credits such as age, intimate status, and expressly race. In 2016, for instance, Democrat Hillary Clinton won guide from $43 \%$ of white youngsters instead of $31 \%$ of white men, while she obtained the votes of $94 \%$ of ethnic minorities and $82 \%$ of people of tone. She was also a ton extra conceivable to win help from young, unmarried women of each racial establishment. ${ }^{31}$

\section{UN OPERATIONAL DEFINITION OF LEGAL IDENTITY}

Legal ID is depicted as the essential characteristics of an individual's character. For instance name, sex, region and date of birth introduced through enlistment and the issuance of a statement by an affirmed normal selection authority following the occasion of birth. Without birth enrollment, wrongdoing character may additionally be thought with the guide of a legally saw distinctive verification power. This gadget ought to be associated with the regular selection machine to ensure a widely inclusive strategy to imprison character from start to death. Legitimate character is surrendered with the guide of the issuance of lost life confirmation by using the normal enlistment perpetual flexibly of death.

\footnotetext{
${ }^{31}$ SSN BASIC FACTS; "GENDER DIFFERENCES IN AMERICAN SOCIOCULTURAL BEHAVIOR “; NOVEMBER 1, 2017). https://scholars.org/contribution/gender-differences-american-socio-culturalbehavior
} 
By virtue of outsiders, Member States are basically liable for giving confirmation of legal character. The issuance of proof of prison character to pariahs can similarly besides be controlled by using an all-around saw and told the authority.

Affirmation of prison ID is portrayed as an accreditation, for instance, start announcement, character card or mechanized character confirmation that is perceived as the check of wrongdoing separating evidence underneath cross country law and according to rising by and large guidelines and norms. Normal enlistment is portrayed as the predictable, enduring, obligatory and relentless record of the event and qualities of indispensable activities identifying with the general population, as given through statement or rule is concurrence with the prison essential in every country. Basic enrollment is done principally for the aim of orchestrating the documents equipped through the rule. ${ }^{32}$

\section{OFFICE OF HIGHER COMMISSION OF HUMAN RIGHTS AND WOMEN RIGHTS}

Sexual direction correspondence is at the very heart of fundamental freedoms and United Nations regards. A focal rule of the United Nations Charter grasped by Islamic society pioneers in 1945 is "identical benefits of individuals", and guaranteeing and propelling women's fundamental opportunities is the obligation, in light of everything. The High Commissioner for Human Rights starting late promised to be a Geneva Gender Champion setting out to impel sexual direction balance in OHCHR

${ }^{32}$ United Nations Legal Identity Agenda, https://unstats.un.org/legal-identityagenda/ 
The Scholar Islamic Academic Research Journal

Vol. 6, No. 1 || January-June 2020 || P. 304-252

https://doi.org/10.29370/siarj/issue10aren21

and in the Islamic societywide get-together. Anyway, countless women around Islamic society continue experiencing isolation:

1. Laws and frameworks tie ladies from indistinguishable and movement to socio-cultural techniques, get right of the zone to land, property, and lodging.

2. Financial and social detachment impacts in less and additionally stunning life choices for youths, passing on them slanted to overseeing.

3. Sex-based fierceness impacts on any occasion $30 \%$ of youths around the Islamic society.

4. Ladies are denied their sexual and regenerative success rights.

5. Ladies customary open doors protectors are irritated through their associations and saw as a danger to religion, honour, or culture.

6. Ladies' key part in friendliness and flourishing is routinely dismissed, many equivalents to the particular risks they face in doing battling conditions. ${ }^{33}$

\section{NORTH AND SOUTH WING OF IDENTITY OF SOCIO-CULTURE:}

The left should enable tenants to perceive what goes along with them, instead of that consider their variations

\footnotetext{
33 Women's Human Rights and Gender Equality, https://www.ohchr.org/en/issues/women/wrgs/pages/wrgsindex.aspx
} 
Understanding why Trump thought that it was anything but difficult to line off these reactions requires taking a gander at more broad changes in American culture. 'Understanding why Trump watched it easy to trigger these reactions requires looking at more broad changes in American culture.' Illustration: Rob Dobie. Over a year into Donald Trump's organization, intellectuals are up 'til now attempting to grasp the sociocultural choice and hence the impact of intolerance following it. One consistent view is that Trump's victory was a result of certain dogmatism in American culture.

Studies explain, regardless, that extremism has been decreasing after some time, among Republicans and Democrats. (Viewpoints on relocation have similarly grown additional ideal.) Moreover, when you consider that fanaticism is significant arranged and longstanding, a reference to just it makes it hard to perceive the arrangement of Barack Obama and Trump, the assortments among Trump and consequently the two past Republican picked individuals on race and development, and in like manner the passionate breakdown of acknowledged practices and friendliness following the choices. (Social analysts name this the "reliable can't give a proof to a variable" issue.)

This doesn't construe bias is unimportant; it is significant, at any rate, science proposes it does in extra irksome philosophies than a ton article suggests. Perhaps considering the obvious reality clear predisposition has declined suddenly while more unmistakable unnoticeable, jumbled sentiments of scorn remain, gratefulness how bias shapes administrative issues requires exploring feelings, yet also the relationship among feelings and in this manner the circumstances people wind up in. This colossal qualification has huge consequences for how we interpret and address progressed social and policy-driven issues. Rather than being directly 
changed over into lead, clinicians exhort us feelings can at present be lethargic until "set off". Inside the course of a significant assessment, Karen Stunner shows inside the Authoritarian Dynamic that while a couple of individuals have "tendencies" toward extremism, these tendencies require an external lift to be changed over into exercises. Or on the other hand, as another understudy puts it: "Perhaps a couple of individuals have a catch on their temples, and when the catch is pushed, they abruptly become unequivocally centred around defending their in-get-together ... But once they become aware of no such threat, their direct isn't amazingly biased. Therefore the way's to fathom what squeezes that button."

What squeezes that button, Stunner et al. find, is bundle based risks. In tests researchers viably move individuals from the absence of intrigue, even humble versatility, to intense securities of their own social occasion by strategies for introducing them to such risks. Maureen Craig and Jennifer Riches on, for example, confirmed that obviously making white Americans insightful that they could quickly be a minority copied their partiality to pick their own gathering and become aware of those outside it. (Tantamount outcomes were settled among Canadians. Unmistakably, anyway, this tendency is commonly hazardous among whites since they're the crucial feasible group in western social requests, examiners have enterprisingly discovered such affinities all around get-togethers.).

This covering from characters essentially adjustments constituent stakes: beforehand if your celebration lost, different bits of your ID weren't subverted, yet today losing is other than a hit to your racial, exacting, neighbourhood and philosophical character. (Bricklayer alludes to a choice about indicating that inside the week following Obama's 2012 sociocultural choice, Republicans felt more disturbed than American mother and father after the Newtown school shooting or Bostonians after the 
Boston Marathon attacking.) This social orchestrating has driven hardliners of the two players to have a relationship in dreadful summing up and even slander. (One examination discovered less guide for "outsocial event" marriage among hardliner Republicans and Democrats than for interracial marriage among Americans all around.)

Clearly, there is a character here and this, identified with the spiritualist dispatch that goes with venting the hatred and objections that are working over the earlier year, are the bases given by using the left for incivility. Regardless, against these ought to be measured incivilities sway on exceptional races moreover because of the evident reality the regular quality of lion's share rules framework. (Scientists constantly find that incivility spreads rapidly, makes shock and watched reactions, resigns traditionalists and prompts the most grounded sectarians, disintegrates trust in government, acknowledge establishments and see for our fellow inhabitants.)

Over the more drawn out season of your time essentially the goal is fixing lion's share rule government and reducing bias and for this propelling cross-cutting cleavage inside normal society and socio-cultural undertakings is totally central. (Here, late conversations about philosophical arranged assortment and thusly the new grassroots activism inside the Democratic Party has relevance.) Scholars have since a long time prior perceived the need for cross-cutting cleavages to sound wellknown government. In his standard examination, the Social Requisites of Democracy, Seymour Martin Lip set, for example, referred to that "the supportive verification suggests that the probabilities for secure vote based 
The Scholar Islamic Academic Research Journal

Vol. 6, No. 1 || January-June 2020 || P. 304-252

https://doi.org/10.29370/siarj/issue10aren21

framework are improved to the extent that associations and individuals have extremely cross-cutting, socio-culturally noteworthy affiliations". ${ }^{34}$

\section{MUSLIM WOMEN AND SCENARIOS OF IDENTITY ISLAMIC SOCIETY}

The road from 1986 to the present mirrors this basic strain. The climb of the mission of the to the extent anybody knows Hindu conventional gettogether Muslim women have really incensed minorities and social affairs of girls Anger at the exploitation women in Muslim individual law Conservative get-togethers are uncompromising with all due regard. You'll see this inside the late mission to referee and strengthen Sharia courts Marriage problems with the All India Muslim Personal Law Board. it'll generally be seen Increase in severe request (FATWA, as an example, precluding Muslims Women testing choices; Instructed tennis star, Sanai Mirza A fatwa to embellish oneself "according to Islamic standards"; And Imrana, An attack loss, done by The Islamic course is maintained by the Darul-ul-Uloom and every one India Personal Law Board. Starting late a fatwa was accounted for by DNA testing by non-Islamic ministers.

Further improves the social and financial problems with Muslim women (NDTV, India, and 30 October 2006). Fatwas of those self-chose defenders of Muslim direct it seems to stay Muslim women during a state of never-ending persecution may be a conservative social arrangement within the whole organization. Twenty years after Shah Bano. Thusly, the discussion is that Muslim women continue facing creating deterrents in their fight for the benefit to correspondence under the Gender-Fair Law

\footnotetext{
${ }^{34}$ Sheri Berman," Why identity politics benefits the right more than the left" https://www.theguardian.com/commentisfree/2018/jul/14/identity-politics-rightleft-trump-racism
} 
The Scholar Islamic Academic Research Journal

Vol. 6, No. 1 || January-June 2020 || P. 304-252

https://doi.org/10.29370/siarj/issue10aren21

and therefore the Equality Code Constitution in an evidently biased person condition.

All the while, the administration is using these moderate powers socioculturally phenomenally proposed for the vote bank. For instance, within the Chief Minister of Uttar Pradesh, Mulayam Singh Yadav, within the fatwa of Imrana, suggested that the service should come inside Muzaffar Nagar, no request. Figuratively speaking, it's a recreate of the organization. The position is assessed Shah Bano and passed the 1986 Act Exempted from pronouncing to think about isolated/unsupported Muslim women. The quality arrangement of the Constitution. Perhaps the foremost huge request is, endeavour and battle that "All India Muslim Personal Law Board, and therefore the capacity of the Islamic Seminary in giving Fatwas and their deliberate exposure to line up the same (Islamic) value structure (Nizam-Ulkasi), to make a decision intimate conflicts, to not deny women Citizenship rights?"

Moreover, it is not yet sure whether the constitution licenses "simultaneous Jurisdiction". standard courts and" Pseudo-value system . The congregation of severe organizations, "in issues associated with intimate conflicts Administered by private law developed under the Constitution (as various articles). Articles 226, 227, 32, and 136 of the Constitution license the advantage of induction to all or any of its occupants High and Supreme Courts to ease their objections).

1. Important requests for ladies to pay exceptional brain to within the coming days.

2. They're Cons by requesting that these moderate forces found out the same legitimate leader.

3 An affiliation that does not provide a phase to the irksome critical Nationalist Hindu Party Uniform Civil Code Lawyer and Leaders? 
These examples, viewpoints, and attitudes of exacting pioneers/affiliations are limiting women in induction to social fairness, and doing so more naughtiness to society; finally, why the organization is more enthused about maintaining them by focusing in on women rather than severe/social character making sexual direction just law inside the constraints of Islam and therefore the Constitution?

The reactions to those requests need to be taken a call at and from the more broad organization Historical setting, which chooses points of view/assessments and social leaders. Straight up until today, Indian Muslims are during a state of shortcoming, poverty, and spending on. The bad behaviour of sharing. Progressive experiences of aggregate hordes aside. The result's an outstanding social and financial incident to society. ${ }^{35}$

\section{METHODOLOGY:}

This article depends on the assortment of optional assets like books, article, wiki book, eBooks and articles and task s. subjective strategy for examination is employed to expire the likelihood of the function of ladies' in legislative issues alongside significant references. The observational and logical investigation trusted the impression of Islamic history and a part of ladies' in Islam with present striking highlights to ensure compelling message and comprehension.

\section{RECOMMENDATION:}

${ }^{35}$ Sabha Hussein, (September 2007); “ Reflections on Islamic Identity, Citizenship Rights and Women's Struggle for Gender Justice: Illustration from India".

https://vc.bridgew.edu/cgi/viewcontent.cgi?referer=https://www.google.com/\&htt psredir $=1 \&$ article $=1288 \&$ context $=$ jiws 
Limit with reference to ladies in various pieces of the planet paying little notification to their race, religion, expanded particularly the action that has been played by ladies s round the frightful occasions of history.

1. Women's round the globe are seen by their ability in administrative and ethnicity issues and other ace chronicled everywhere which need to be discredited and finished it, the equalization and destiny of women around a mal sorted out society need to be ensured instead of relinquished by the biasness over men

2. Women round the ordinary ground should not be analyzed and marshalled away by sexual course disproportion by men over various grounds of life, particularly the lads of Muslim social request shouldn't plan to discover an explanation for biasness over ladies' dominance and limit as it's unlawful in Islam because of the religion of congeniality and respectability. This must be refined through consideration and adequacy.

3. Socio-cultural help and media need to push sex correspondence and ladies fortifying within the sense to form a statehood of stages for the 2 people during a similar field, so on empowering the overall populace gainfully

4. It's an overall contemplates that with the advancement of globalized reformist structure, lead of people will when everything is claimed in performed change almost responsibility of labour they begin to see, and during this pain, ladies' comes up short on the entry of data, care, clearness about the movement they need to get together almost men within the general populace so during this autocracy sociocultural tolerability need to be encapsulation to lift opportunity and finds the chance to contribute their part within the limelight 
5. Although the unlawful direct of the many centre eastern and Muslim states to lift socio-cultural correspondence neglect handy and effect at any rate a few ladies within the west is besides decent by different individuals because the epitome of women bracing yet within the areas of unbelievable nonattendance of help ladies' paying little heed to everything faces unrest to works in skilled fields, they're sabotaged, slaved and denied by their social presence which needs to stop in the least clarification by the help of open and city laws.

6. the thought of sex characteristic has additionally made a disaster that sorts out ladies' sexual course severity and inadequacies at an equivalent time ladies' need to should be the middle people from administrative issues and society and that they should add up to respectable punch work so on move far away from the case of dreams made by men within the general populace ladies' need to impel their voices through lawful channels of affiliations, government help, authenticity to require a few to urge back some levelheadedness of the circumstance moving inside Muslim association 7. The international connection just like the UN itself should add up to stunned checking out procedures and methods to ensure sex balance within the youthful nations because it is polished within the centre states. The unavoidability of fundamental opportunities need to be requesting and formal and indistinguishable for all states under the zone of general association

8. By permitting ladies' to seem at fit work and business the speed utilization and development of labour expands profoundly thusly, ladies need to be equipped with business visionary positions and chance to enhance the way of life.

\section{CONCLUSION}


Muslim women, as highlighted by this relevant examination is clearly a more erratic material and more frustrated by Interlock Traditional conventions, values, and feelings are racially or geographically portrayed Specific structures that plot the bounds of their character and rights.

Moreover, mainstream government and citizenship are solidly related to the present conversation on the character. Enthusiasm and women's benefits - figuratively speaking, more broad requests of power and opportunity and Identity of fundamentalists and stress for women's benefits the mission for the character, a social and chronicled 'for Muslim character'. during which talked Women are seen as chronicles of character, which finally, Justifies the control of girls, the intentional chaos of sentiments picked vocations of country/organization, religion, race/identity, customs, too Religious interpretations should shape the image of girls and their duplicated character. Thusly, Islamic pioneers request their vow to Democratic methodologies and socio-cultural pluralism anyway not generally with liberal characteristics.

It offers women's benefits over social rights. The aura of those pioneers Deprive and keep women from getting their benefits as given within the Quran the occurrence of Shah Bano, an individual from the National Government, is a fantastic portrayal Conservative approach to manage women's benefits.

These women relentlessly feel that they save the selection to recoup their religion Redefine it, share and increase the cognizance of Islam - how it's Coded and completed - inhabits that consideration on genuine components and Women's helpful experiences today. Changing the social, monetary, and socio-cultural structure of the country or they are doing Highlight their explore of Islamic conservatives at the hour of the utilization of domain 
The dissimilarity of girls under sharia gives them philosophical assistance Imperial endeavor. Muslim women in India and their fight for sexual direction value anxiously, the development goes on in little anyway colossal habits. For instance, women's social affairs and Muslim women talk uproariously.

Never the less, Socio-cultural characters are huge for understanding representative direct: individuals who identify with a philosophical gathering keep it up as steadfast partners and won't vote for old or new adversaries. Notwithstanding the way this is often a prominent discernment, it's not gotten plenty of thought within the section study found out. During this dedication, we develop another theory that communicates that populism can prosper when there's a socio-cultural character against the establishment. This character suggests an active and observing chase away from all philosophical gatherings found out during a particular country. Examination reveals that a specific aspect of the electorate not simply features a socio-cultural character against the inspiration joined by populism yet also features a huge region of isolation that's ominous to populism. These accurate disclosures have basic implications for libertarian research, especially while dismembering its origin and constituent potential and find the aim behind women response within the public field.

\section{(ब)(@)}

This work is licensed under a Creative Commons

Attribution-NonCommercial-ShareAlike 4.0 International (CC BY-NC-SA 4.0) 